
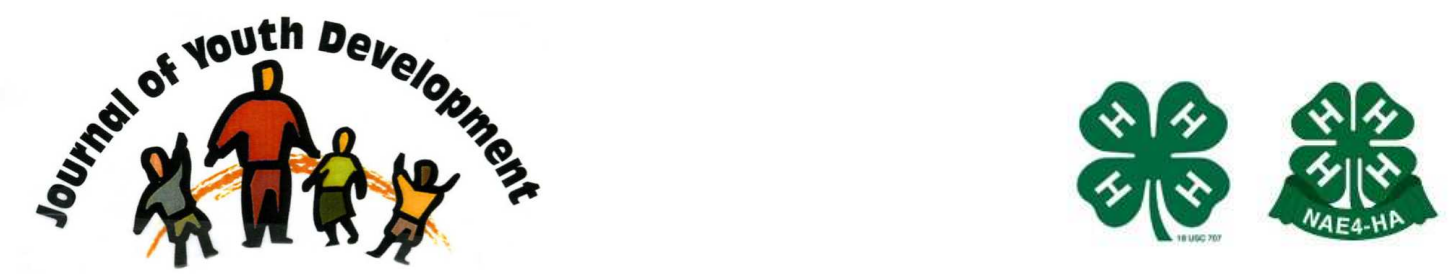

Bridging Research \& Practice

\title{
The Evolving Role of Youth Workers
}

Lynne M. Borden

University of Arizona

bordenl@ag.arizona.edu

Gabriel L. Schlomer

University of Arizona

Christine Bracamonte Wiggs

University of Arizona 


\title{
JOURNAL OF YOUTH DEVELOPMENT \\ bridging research and practice

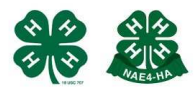

Volume 6, Number 3, Fall 2011

Article 110603FA008

\section{The Evolving Role of Youth Workers}

\author{
Lynne M. Borden, Gabriel L. Schlomer and Christine Bracamonte Wiggs \\ University of Arizona
}

\begin{abstract}
In reviewing the field of youth development, of which youth workers are a part, it is clear it has had a long and complex history that is intertwined with other disciplines. More recently youth workers have experienced a transformation of sorts, with youth programs in the past being seen exclusively as a place to play and have fun, whereas today's expectations include a much broader focus on the overall positive development of young people. This evolution has been heavily influenced by a number of societal changes that have placed increasing demands on youth programs. Today's youth workers are faced with the responsibility to promote a young person's development which often includes supporting academic success and graduation from high school, reducing risk-taking behaviors, increasing positive health attitudes, and more. Youth workers have seen their role change dramatically over the past 20 years with greater demands and increased accountability.
\end{abstract}

\section{Introduction}

The field of youth development, of which youth workers are a part, has a long and complex past that has often intertwined with other disciplines such as psychology, social work, education, and others. Over time, many of these disciplines have changed and evolved in an effort to effectively respond to societal demands. Youth workers are currently experiencing their own similar transformation. Youth programs of the past were often seen exclusively as a place to play and have fun; however, today the expectations for youth workers and programs include the promotion of the overall positive development of the young people within the program.

To understand the evolving role of youth workers one must first consider the varying contexts in which they work and the roles (e.g., youth pastor, corrections professional, nurse, teacher, public health worker, and others) they play within their organizations. The International Child and Youth Care Consortium offers a definition that provides at least an initial understanding of the complex, multi-dimensional nature of today's professional child and youth workers: 
Professional Child and Youth Care Practice focuses on infants, children, and adolescents, including those with special needs, within the context of the family, the community, and the life span. The developmental-ecological perspective emphasizes the interaction between persons and their physical and social environments, including cultural and political settings. Professional practitioners promote the optimal development of children, youth, and their families in a variety of settings, such as early care and education, community-based child and youth development programs, parent education and family support, school-based programs, community mental health, group homes, residential centers, day and residential treatment, early intervention, home-based care and treatment, psychiatric centers, rehabilitation programs, pediatric health care, and juvenile justice programs. Child and youth care practice includes assessing client and program needs, designing and implementing programs and planned environments, integrating developmental, preventive, and therapeutic requirements into the life space, contributing to the development of knowledge and practice, and participating in systems interventions through direct care, supervision, administration, teaching, research, consultation, and advocacy (National Organization of Child Care Worker Associations, 1992, p. 83).

Given the diversity of the contexts in which they work and the variety of duties they perform, it is clear that the role of the youth worker is complex. For the purposes of this paper we will define a youth worker as anyone who develops/implements places/programs designed to fill the discretionary time of young people with opportunities for socialization and learning (Perkins \& Borden, 2001).Young people who participate in these contexts can build important life skills, develop positive youth-adult and peer-peer relationships, and engage in activities that promote their overall positive development (Eccles \& Gootman, 2002; Lerner, 2004; Perkins \& Borden, 2003; Villarruel, Perkins, Borden, \& Keith, 2003).

\section{Youth Workers from an Historical Perspective}

The role of youth workers can be traced back more than 100 years in the history of the United States. Many youth programs were created in response to two major societal changes. Specifically, the decline in the number of children needed as part of the labor force and the enactment of the compulsory education laws (Halpern, 2002). These changes led to a shift in how children and youth used their time, now splitting their time between the hours spent in school and discretionary time (e.g., time not spent in school) (Halpern, 2002). The increase in discretionary time led to an increase in the number of children and youth on the streets engaged in non-productive activities. The influx of children on the streets was seen as a problem that needed to be addressed. The result was not only new laws (e.g. curfews, loitering), but new ideas regarding how to provide for the needs of children and youth (Halpern, 2002). Together these forces created the need for organized programs, many of which continue to exist today.

One such program, established in 1856, was the first "student" Young Men's Christian Association (YMCA) (Young Men's Christian Association: 1800s - 1860s, 2011). Soon this led to the development of a number of "boys' clubs" which began to emerge in the 1860s. The boys' clubs were designed to offer young boys a positive alternative to being on the streets (Boys and Girls Clubs of America, 2011). Other programs were created to address the needs of youth such as the 4-H program, an informal educational program to promote youth development, established between 1890 and 1900 (Iowa 4-H, 2011) and the Girl Scouts of the United States 
of America (GSUSA), founded by Juliette Gordon Low in 1912 to promote community service and empowerment of young girls (Girl Scouts, 2011).

Historically young people have had the opportunity to interact with and learn from non-familial adults in their lives through both formal and informal teaching within various contexts (e.g., formal and informal settings). In the United States, adults and youth began to interact in more formalized settings (e.g., school, faith-based settings). This tradition continued with the implementation of youth programs as these depended heavily on adult volunteers to develop and run the programs. This model of volunteer-driven programs for youth continues today, however, societal changes have required many organizations to change the manner in which they now deliver programming including those that have chosen to move their programs to within the school day (e.g., Junior Achievement). Regardless of the model, youth programs offer non-familial adults and youth the opportunity to interact, work together, and learn from one another.

\section{Understanding the Field of Youth Development}

By examining the field of youth development, one is able to understand the important role that the youth worker plays. The field of youth development evolved from a variety of disciplines including psychology, sociology, education, and others. The field was further defined by the research on youth resiliency: the ability of youth to withstand the stressors of life by drawing upon personal attributes, affectionate ties, and external support systems. Examination of youth resiliency has provided practitioners with information about the qualities of youth and their environments that buffer them against adversity. The research on resiliency has led practitioners to use this information to promote positive youth development within various settings (Perkins, Borden, Keith, Hoppe-Rooney, \& Villarruel, 2003). The research pertaining to youth resilience also has a long and rich history that notes the most common protective factor is the presence of a caring non-parental adult in a young person's life (Rutter 1987; Werner \& Smith, 1982).

Youth work practitioners play an important role in a young person's life through their provision and enhancement of programs that offer youth an opportunity to engage in activities that encourage their active involvement in their own development (Walker, Marczak, Blyth, \& Borden, 2005); these experiences are essential to their positive development. Lerner and Hertzog (2003) further described the role of community youth development professionals/youth workers noting that:

A community youth development professional is envisioned to be a community builder on behalf of youth development. He or she would identify and integrate the strengths of young people and the assets of communities to create a set of actions that would provide for youth: (1) positive, healthy, and sustained adult-youth relations; (2) skill building opportunities in youth; and (3) opportunities for youth to participate in, and take leadership of, community-based activities by and for youth. The work of community youth development professionals would put young people on a life path marked by the "Five Cs" of positive youth development (Competence, Confidence, Connection, Caring, and Character) that would eventuate in the person becoming an adult making contributions (the "Sixth C" of positive youth development) to self, family, community, and civil society (p. 1). 
There is an ever-growing body of literature that supports the role of youth workers in engaging youth and assisting them in their own development as one way to enhance their positive development (Foster-Fishman, Deacon, Nievar and McCann, 2005; Wong, Zimmerman, \& Parker, 2010; Zeldin, 2004). Shernoff and Vandell (2007) examined youth engagement in a variety of afterschool enrichment programs (e.g., sports and arts) among eighth grade students. They found that youth reported being most engaged in activities that involved both peers and adults, compared to activities involving peers alone.

Caring adults serve as mentors for youth (Hirsch, 2005), demonstrating effective social skills for positive interaction with others and fostering a sense of self-worth (Serido, Borden, \& Perkins, 2009). Messias, Fore, McLoughlin, and Parra-Medina (2005) noted that in programs that empower youth, adults "provided encouragement and advice, gave specific guidance and directions, and created opportunities for youth to utilize their own potential as well as reflect on their own actions" (p. 334). However, in a study investigating why youth, particularly youth of color, chose not to participate in youth programs, Borden, et al. (2006) found that a frequently cited reason for lack of participation was a poorer quality relationship with adult staff. Taken together, these findings suggest that youth-adult partnering in programs may form the foundation that will reduce the perceived barriers to continued program participation. It is clear that the role of the youth worker is critical and has the potential to positively influence the lives of young people.

\section{Understanding the Important Role of Youth Workers}

The ever-changing role of youth workers requires an understanding of how this work will continue to evolve over the next few years and beyond. Gaining this insight requires addressing the tension that exists between how a profession is generally defined and whether youth workers are categorized as professionals. This particular debate is often at the heart of much heated discussion. There are those who believe that youth workers and the field cannot progress forward without some type of movement toward professionalization and others who believe professionalization is more about status and the requirements of the workforce, the occupational class, and a certain group of people educated and trained to do the work (Lochhead, 2001; Lyon, \& Canning, 1990). To simply ignore this tension would be inappropriate as the role of youth workers will be directly influenced by this debate. Far too often, as one administrator reported regarding the qualifications required for youth workers, only "the ability to fog a mirror" (Stuck, 1994, p. 60) was required for employment with his agency. While the role of youth workers has slowly begun to transform and youth workers have begun to be recognized for their contributions, the transition from an all-volunteer basis to a more professionalized structure has been difficult.

The call for professionalization of youth workers has been ongoing since the early 1970s (see Ferguson \& Anglin, 1985 for a review) and proponents of professionalization have traditionally cited issues related to the perception of low status, low pay, and limited opportunity for advancement for youth workers (e.g. Beker, 1975; Christiansen, 1996; Lochhead, 2001). Proponents of the professionalization of youth workers contend that increasing pay would likely result in a reduction in the staff turnover rate. Higher salaries and benefits for program staff would provide an incentive to stay in the job longer, increase the number of individuals who choose to work in the field, and reduce the number of employees who leave the field for other professions. A recent survey from the Next Generation Work Coalition titled Growing the Next Generation of Youth Work Professionals: Workforce Opportunities and Challenges (Yohalem, Pittman, \& Moore, (2006) indicates that 
(1) career advancement in the youth worker field requires job changes indicating limited opportunities for advancement,

(2) three-fourths of youth workers report that compensation is the primary factor they consider when deciding to leave the field, and

(3) both youth workers and directors agree that raising wages is the most important factor in advancing the profession (Starr, Gannett, Garza, Goldstein, \& Yohalem, 2008).

Staff turnover hovers around $40 \%$ annually and youth workers tend to be young and leave the occupation early due to a lack of opportunities for advancement (Halpern, 2002).

Addressing the issue of staff turnover is critical, as the repeated turnover of staff leads to programs with less continuity requiring young people to repeatedly establish new relationships with new youth workers. Thus, one implication of reduced staff turnover for youth workers is that better relationships and bonding are more likely to occur between program staff and program participants. Caring relationships between program staff and youth directly influence youths' decisions to attend programs (Borden, et al. 2006; Rhodes, 2004). In addition, forming bonds with youth can promote developmental benefits. For example, Hirsch and colleagues (2000) found that staff-participant relationships can help develop confidence and self-esteem through role modeling. Indeed, in one program a youth directly lamented staff turnover indicating that all the "good staff" leave (p. 220), referring to "good staff" as those individuals who are able to connect with youth (Hirsch, et al., 2000). Furthermore, staff directly influence the intellectual and emotional climate of a program and therefore impact program quality.

Currently, "low wages and part-time hours driven by tight budgets, along with the limited supply of qualified youth workers, combine to make staff shortages and retention one of the largest continuing challenges for afterschool programs." (Grossman, et al., 2002; p. vi). A comprehensive study of youth program staff showed that only $20 \%$ of workers say their organization formally recognizes or rewards participation in training and only $62 \%$ indicate that their organization pays for training (Yohalem, et al., 2006). The lack of incentives for training may lie in the fact that there is high staff turnover. Youth workers that do not view their work as a profession may have little motivation to seek additional training in their field, especially if the training comes at their own cost. In addition, employers may feel little need to invest in the professional development of their staff due to historically high rates of staff turnover.

While increasing youth worker compensation and benefits may seem appealing, there are several considerations that must be addressed before attempting such a transition. Feasibility, for example, may be a primary challenge to increasing youth workers' salaries. Where is the additional compensation to come from? Central to this point, Lochhead (2001) cautions that increasing salaries may price youth workers beyond the means of the people that need assistance the most. Indeed, some authors argue that the professionalization of youth workers may serve only to estrange youth workers from the populations that they work with through changes in status and workforce specialization (Lochhead, 2001; Lyon, \& Canning, 1990).

Furthermore, even if youth workers received increased training, education, and commensurate salaries, there still remains limited opportunity for career advancement for youth workers. These factors make arguments about quality of care and staff turnover a moot point since youth workers are still likely to leave the field to advance their careers. The structure of the current youth worker system would have to be remodeled to provide such an advancement structure. The results of such a structural change could have profound implications for the quality of care that children and youth receive. For example, currently the large majority (81\%) 
of youth workers are satisfied with their jobs and most (84\%) plan to continue to work with youth for the next five years (Evans \& Sicafuse, 2009). Presently, most youth workers are employed full time (73\%) and part-time workers report levels of job satisfaction similar to workers who are employed full time (Evans \& Sicafuse, 2009; Yohalem, \& Pittman, 2006). Increasing the level of compensation that youth workers receive may open the door for reduced quality of care by attracting employees who place a greater priority on compensation than on the children and youth they work with. Given the level of job satisfaction under the current system and the quality of care provided by current youth workers, there may be little incentive to further professionalize the field. Moreover, a recent trend toward professionalization of youth workers has led to fewer volunteers and part-time workers compared to paid full-time employees. Relying on volunteers and part-time employees has the advantage of providing a more diverse workforce of youth workers who possess a variety of different skills and knowledge that can be passed on to youth (Halpern, 2002). In this view, high staff turnover may not be considered a negative aspect of the current system since youth can take advantage of being exposed to a variety of caring adults.

\section{Professional Practice}

The professionalization of the youth worker role can be distinguished from the more complex issue of the nature of the youth worker profession. While debate exists regarding the professionalization of the field, a separate question exists, namely, what does it actually mean for a youth worker to be a professional? Hahn and Raley (1998) suggest that a professional has "a monopoly of judgment over their clients based on knowledge and expertise" (p. 391). Accordingly, the youth worker professional maintains a privileged position with youth that encompasses responsibilities such as trust, loyalty, and confidentiality as a result of their expertise and the relationship that they have developed with the youth. Consistent with this notion, Sercombe (2010a), building from the work of Koehn (1994), suggests that a professional is based on a relationship with clients, in this case youth, wherein the youth worker makes a commitment to the well-being of youth. The youth work practitioner can be seen as a partner to youth, who from their position of experience and expertise, facilitates transformations in youth by improving and enriching their lives. The youth worker cultivates an environment of trust which permits youth to be vulnerable (Sercombe, 2010b). As a result of this vulnerability, it is a major responsibility of youth workers to act in the best interests of the youth, regardless of the interests of other clients such as funders or stakeholders. Thus, youth workers not only serve in an instructional capacity to youth, but also serve as a confidante, ally, and advocate for youth.

The effort and commitment to youth that it takes to be a successful youth worker is no small task. Individuals who are attracted to this line of work must have an intrinsic want to improve the lives of young people. This desire is likely the reason that the youth worker field has historically consisted of many volunteers who are not in it for the money but rather for the wish to serve youth. However, more must be done in the youth worker field to recruit and retain quality youth work practitioners. Perhaps Walker (2002) framed the situation best: "Passion brings people to youth work, but it takes more than passion to keep them there" (p. 382). One such strategy that moves beyond providing material incentive is the development of youth worker culture (Hahn \& Raley, 1998). In many fields an occupational culture exists that facilitates commitment to the field itself. Often commitment to the field is the result of a selfidentification of the individual to the occupation. One such example is the military. In a study of West Point cadets, Franke (2000) found that the training and education received by cadets served to increase their military identity. That is, greater exposure to military training at the 
academy increased the degree to which they self-identified with the military. Critically, greater military identity was associated with greater commitment to the military as a professional career. Similarly, perhaps a greater research focus could be allocated toward understanding those factors that increase occupational self-identification to create a youth worker culture centered on commitment to the profession and subsequently to the youth they serve.

\section{Future Trends in the Field}

\section{Training and Education}

Youth do not ubiquitously benefit from participating in youth programs. Indeed, there is a relation between the positive benefits youth obtain from program participation and the quality of the program. Essentially, youth benefit from high quality programs and may not benefit from programs that are lower in quality. (e.g. Catalano, Berglund, Ryna, Lonczak, \& Hawkins, 1998; Durlak \& Weissberg, 2007; Vandell \& Pierce, 2001). Much research implicates the role of the youth worker in creating a high quality program and the training and education of youth workers is essential for delivering programs that maximize benefits to youth (Mahoney \& Stattin, 2000; Pierce, Hamm, \& Vandell, 1999). Thus, one trend that will be observed within the youth worker field is an increase in their training and education. One such advancement may come in the form of training certificates much like the CASE program implemented at the University of California, Irvine (Hinga \& Mahoney, 2010). The CASE program consists of university-level courses and fieldwork aimed at educating youth program educators on out-ofschool learning, human development, multicultural education, developing out-of-school curricula, and other courses in teaching math, arts, and coaching sports. College students and current youth workers can complete the program to obtain a certificate in afterschool education.

\section{Professional Development that Transcends Programs}

Another example of advanced training that is focused specifically on improving the quality of programming for adolescents is the Moving Ahead curriculum (Huebner, Walker, \& McFarland, 2003). In many youth programs the extent of training is focused solely on the goals or mission of the program. This structure creates an idiosyncratic system of training wherein youth worker training is specific to the objectives of the program. The Moving Ahead curriculum represents an integration of research, theory, and practice developed to help youth workers critically reflect on their work in an effort to improve program quality. This training curriculum transcends the idiosyncratic nature of typical program training by incorporating a framework based on a fundamental understanding of the nature of youth work. Participants are engaged in shared learning processes and lessons are constructed around the following question: "Here is a principle supported by research and practice. If you accept this principle as valuable, what does it mean for the way you work?" (Huebner, et al., 2003; p. 215). Programs such as the ones described above will be critical in advancing the future of the field and providing high quality programming for youth.

\section{Compensation}

Along with increases in training and education, the compensation that youth workers receive will also increase. This increase will likely not be dramatic; indeed the mismatch between youth workers' compensation and their education and previous work experience will likely persist. Yohalem, Pittman, and Edwards (2010) however suggest that small increases in wages may make a difference in the staff turnover. In addition to small increases in wages, more creative methods of addressing compensation concerns may also follow including loan forgiveness, 
education stipends, credit union access, and financial advising to name a few (Yohalem, et al., 2010).

In total, with the current trends toward increased training, education, and compensation for youth workers it would appear that the overall trend toward the professionalization of the youth worker field will continue.

\section{Conclusions}

The field of youth work has a long and rich history that has been impacted by societal changes that have been shaped by the needs of children, youth, and families. As a result of the changing field of youth development, the role of the youth worker has also changed. Today's youth work practitioners reside in a diverse set of fields and settings, activities, and enterprises. A troublesome reality for the youth worker is the mismatch in compensation relative to training, education, and experience. One way to ameliorate this discrepancy is the professionalization of the field. Professionalization centers on increasing the compensation, status, and benefits of the youth worker as well as the structure of the youth worker field. Barriers to professionalization include the feasibility of such a structural change as well as the limited financial capacity of the field itself. Nonetheless, as time goes on the movement toward professionalization will likely continue and with it further changes in the role of the youth worker. In today's society the needs of youth are focused on the development of positive characteristics. As we move forward, new avenues of youth development may manifest. What these avenues will consist of only the future can tell. However, given the historically adaptive role of the youth worker, these challenges and opportunities should be met with optimism.

\section{References}

Beker, J. (1975). Development of a professional identity for the child care worker. Child Welfare, 54, 421-431.

Borden, L.M., Perkins, D.F., Villarruel, F.A., Carlton-Hug, A., Stone, M.R., \& Keith, J. (2006). Challenges and opportunities to Latino youth development: Increasing meaningful participation in youth development programs. Hispanic Journal of Behavioral Sciences, 28, 187-208.

Boys and Girls Clubs of America: Our History. (2011) Retrieved January 24 ${ }^{\text {th }}, 2011$, from http://www.bgca.org/whoweare/Pages/History.aspx

Catalano, R.F., Berglund, M.L., Ryan, J.A.M., Lonczak, H.S., \& Hawkins, J.D. (1998). Defining and evaluating positive youth development. In Positive Youth Development in the United States: Research Findings on Evaluations of Positive Youth Development Programs.

Christiansen, M. (1996). We need a new profession - not just an upgraded direct care worker!: A response to Shealy. Child \& Youth Care Forum, 25, 305-309.

Durlak, J.A., \& Weissberg, R.P. (2007). A meta-analysis of after school programs that seek to promote personal and social skills in children and adolescents. Journal of Educational Psychology, 36, 211-221. 
Eccles, J., \& Gootman, J.A. (2002). Community programs to promote youth development. Committee on Community-Level Programs for Youth. Board on Children, Youth, and Families, Commission on Behavioral and Social Sciences Education, National Research Council and Institute of Medicine. Washington, D.C.

Evans, W.P., \& Sicafuse, L.L. (2009). 4-H youth worker characteristics: Comparisons with workers from other youth serving organizations. Journal of Extension, 47, 1-8.

Ferguson, R.V., \& Anglin, J.P. (1985). The child care profession: A vision for the future. Child Care Quarterly, 14, 85-102.

Foster-Fishman, P., Deacon, Z., Nievar, M.A., \& McCann, P. (2005). Using methods that matter: The impact of reflection, dialogue and voice. American Journal of Community Psychology, $36(3 / 4)$, 289-301.

Franke, V.C. (2000). Duty, honor, country: The social identity of West Point cadets. Armed Forces \& Society, 26, 175-202.

Girl Scouts: Juliette Gordon Low biography. (2011). Retrieved January $24^{\text {th }}, 2011$ from http://www.girlscouts.org/who we are/history/low biography/.

Grossman, J.B., Price, M., Fellerath, V., Jucovy, L., Kotloff, L., Raley, R., \& Walker, K. (2002). Multiple Choices After School: Findings from the Extended-Service Schools Initiative. Philadelphia, PA: Public/Private Ventures Report.

Hahn, A.B., \& Raley, G.A. (1998). Youth development: On the path toward professionalization. Non-profit Management \& Leadership, 8, 387-401.

Halpern, R. (2002). A different kind of child development institution: The history of after-school programs for low-income children. Teachers College Record, 104 (2), 178-211.

Hinga, B.M., \& Mahoney, J.L. (2010). Preparing the next generation of after-school educators: College students' percieved learning and civic engagement associated with the CASE program. Journal of Youth Development, 5(3).

Hirsch, B.J. (2005). A place to call home: After-school programs for urban youth. Washington, D.C.: American Psychological Association.

Hirsch, B.J., Roffman, J.G., Deutsch, N.L., Flynn, C.A., Loder, T.L., \& Pagano, M.E. (2000). Inner-city youth development organizations: Strengthening programs for adolescent girls. Journal of Early Adolescence, 20, 210-230.

Huebner, A.J., Walker, J. A., \& McFarland, M. (2003). Staff development for the youth development professional: A critical framework for understanding the work. Youth Society, 35, 204225.

Iowa 4-H: History of 4-H. (2011). Retrieved January $24^{\text {th }} 2011$ from http://www.extension.iastate.edu/4h/explore/History4h.htm.

Koehn, D. (1994). The Ground of Professional Ethics. London: Routledge. 
Lerner, R.M. (2004). Liberty: Thriving and civic engagement among America's youth. Thousand Oaks, CA: Sage Publications.

Lerner, R. M. \& Hertzog, S. M. (2003). Creating a community youth development profession: From vision to instantiation. Medford, MA: Tufts University.

Lochhead, A. (2001). Reflecting on professionalization in child and youth care. Child \& Youth Care Forum, 30, 73-82.

Lyon, M.E., \& Canning, P.M. (1990). Professionalizing day care. In J.P. Anglin, C.J. Denholm, R.V., Ferguson, \& A.R. Pence (Eds.), Perspectives in Professional Child and Youth Care (pp. 187-198). New York: Hawthorne Press.

Mahoney, J.L., \& Stattin, H. (2000). Leisure activities and adolescent antisocial behavior: The role and structure of social context. Journal of Adolescence, 23, 113-127.

Messias, D.K.H., Fore, E.M., McLoughlin, K., \& Parra-Medina, D. (2005). Adult roles in communitybased youth empowerment programs. Family and Community Health, 28(4), 320-337.

National Organization of Child Care Workers Association. (NOCCWA; 1992). The international leadership coalition for professional child and youth care: Milwaukee. Journal of Child and Youth Care Work, 8, 69-83.

Perkins, D.F., \& Borden, L.M. (2001). Programs for adolescence. In R.M. Lerner \& J.V. Lerner (Eds.) Adolescence in America (pp. 535-540). Santa Barbara, CA: ABC CLIO.

Perkins, D.F., \& Borden, L.M. (2003). Risk factors, risk behaviors, and resiliency in adolescence. In R.M. Lerner, M.A. Easterbrooks, \& J. Mistry (Eds.), Handbook of psychology: Vol. 6 Developmental psychology (pp. 373-394). New York: Wiley.

Pierce, K.M., Hamm, J.V., \& Vandell, D.L. (1999). Experiences in after-school programs and children's adjustment in first-grade classrooms. Child Development, 65, 440-457.

Rhodes, J.E. (2004). The critical ingredient: Caring youth-staff relationships in after-school settings. New Directions for Youth Development, 101, 145-191.

Rutter, M. (1987). Psychological resilience and protective mechanisms. American Journal of Orthopsychiatry, 57, 316-331.

Sercombe, H. (2010a). Youth workers as professionals: Managing dual relationships and maintaining boundaries. In Banks, S. (Ed.), Ethical Issues in Youth Work (2 ${ }^{\text {nd }}$ ed.) (pp. 77-91). New York, NY: Routledge.

Sercombe, H. (2010b). Youth Work Ethics. Thousand Oaks, CA: Sage Publications.

Serido, J., Borden, L.M., \& Perkins, D.F. (2009). Positive youth/adult relationships promoting youth voice: a pathway to positive youth development. Youth \& Society, DOI:

$10.1177 / 0044118 \times 09351280$. 
Shernoff, D.J., \& Vandell, D.L. (2007). Engagement in after-school program activities: Quality of experience from the perspective of participants. Journal of Youth and Adolescence, 36, 891903.

Starr, E., Gannett, G., Garza, P., Goldstein, S., \& Yohalem, N. (2008). Clear policies for career pathways: Lessons learned. Next Generation Youth Work Coalition.

Stuck, E.N. (1994). The future of child and youth care as a profession: Assessing administrator attitudes. Journal of Child and Youth Care Work, 9, 56-65.

Vandell, D.L., \& Pierce, K.M. (2001). Experiences in after-school programs and child well-being. In J.L. Mahoney (Chair), Protective aspects of after-school activities: Processes and mechanisms. Paper symposium conducted at the biennial meeting of the Society for Research in Child Development, Minneapolis, MN.

Villarruel, F.A., Perkins, D.F., Borden, L.M., \& Keith, J.G. (2003). Community youth development: Practice, policy, and research. Thousand Oaks, CA: Sage.

Walker, J.A. (2002). The essential youth worker: Supports and opportunities for professional success. In Villarruel, F.A., Perkins, D.F., Borden, L.M., \& Keith, J.G. (Eds.), Community Youth Development: Programs, Policies, and Practices (pp. 373-393). Thousand Oaks, CA: Sage Publications.

Walker, J., Marczak, M., Blyth, D., \& Borden, L. (2005). Designing youth development programs: Toward a theory of developmental intentionality. In Mahoney, J. L., Larson, R. W., \& Eccles, J. S. (Eds.), Organized activities as contexts of development: Extracurricular activities, after-school, and community programs (pp. 399-418). Mahwah, NJ: Lawrence Erlbaum.

Werner, E., \& Smith, R. (1982). Vulnerable but invincible: $A$ study of resilient children. New York: McGraw-Hill.

Wong, N.T., Zimmerman, M.A., \& Parker, E.A. (2010). A typology of youth participation and empowerment for child and adolescent health promotion. American Journal of Community Psychology, 46, 100-114.

Yohalem, N., \& Pittman, K. (2006). Putting youth work on the map: Key findings and implications from two major workforce studies. The Next Generation Youth Work Coalition, 110.

Yohalem, N., Pittman, K., \& Moore, D. (2006). Growing the next generation of youth work professionals: Workforce opportunities and challenges. Houston, TX: Cornerstones for Kids.

Yohalem, N., Pittman, K., \& Edwards, S.L. (2010). Strengthening the youth development/afterschool workforce: Lessons learned and implications for funders. Washington, D. C.: The Forum for Youth Investment.

Young Men's Christian Association: 1800s - 1860s (2011). Retrieved January $24^{\text {th }} 2011$ from http://www.ymca.net/history/1800-1860s.html. 
Zeldin, S. (2004). Youth as agents of adult and community development: Mapping the process and outcomes of youth engaged in organizational governance. Applied Developmental Science, $8(2), 75-90$.

(c) Copyright of Journal of Youth Development $\sim$ Bridging Research and Practice. Content may not be copied or emailed to multiple sites or posted to a listserv without copyright holder's express written permission. However, users may print, download or email articles for individual use. 